\title{
Association of the Glutathione S-transferase T1 Null Genotype with Risk of Gastric Cancer: a Meta-analysis in Asian Populations
}

\author{
Yan Zeng ${ }^{1 \&}$, Jian Bai ${ }^{2 \&}$, Li-Cong Deng ${ }^{3 \&}$, Yu-Ping Xie ${ }^{2}$, Fen Zhao ${ }^{2}$, Ying Huang ${ }^{1 *}$
}

\begin{abstract}
Background: A large number of studies have been published to investigate the association between the null genotype of glutathione S-transferase T1 (GSTT1) with gastric cancer. However, the results were inconsistent and conflicting. The aim of this study was to estimate the relationship between this polymorphism in the GSTT1 gene and gastric cancer risk in Asian populations by meta-analysis. Materials and Methods: A literature search was performed in PubMed, Embase, Chinese Biomedical database (CBM), Weipu database, Wanfang database, and China National Knowledge Infrastructure database (CNKI). Statistical analysis was conducted by using Review Manager 5.3. Results: Thirty-nine studies with a total of 7,737 gastric cancer cases and 10,823 controls were included in this meta-analysis. The meta-analysis of total studies showed that the null genotype in GSTT1 was associated with increased risk of gastric cancer in Asians ( $O R=1.19,95 \% \mathrm{CI}=1.08-1.31, p=0.0002)$. Subgroup analysis showed a significant relationship between GSTT1 null genotype and gastric cancer in East-Asians, as well as in subgroup analysis of hospital-based design. On subgroup analysis by smoking status, alcohol status, Helicobacter pylori infection status, and histology type, no significant association of this polymorphism with susceptibility to gastric cancer was found. Conclusions: In conclusion, the results showed that the null genotype of GSTT1 is significantly associated with an increased risk in gastric cancer in Asian populations.
\end{abstract}

Keywords: GSTT1 - polymorphism - gastric cancer - meta-analysis - Asia

Asian Pac J Cancer Prev, 17 (3), 1141-1148

\section{Introduction}

It is estimated that by 2020 , more than 15 million cases of cancer will occur in the world, with deaths increasing to 12 million (Kanavos, 2006). According to the report, gastric cancer is the fourth most common malignancy among worldwide and the second leading cause of global cancer death, which has a high incidence in Asia, especially in Eastern Asia (Jemal et al., 2011). Identifying risk factors for gastric cancer development is essential to prevent this deadly disease. Numbers of studies have been shown that gastric cancer is a disease of multiple etiologic factors involving infectious, nutritional and environmental factors (Setiawan et al., 2000; Tripathi et al., 2011; Shi et al., 2014). However, the regional differences in the incidence of gastric cancer worldwide might imply that variants in various genetic factors also influence the susceptibility to this disease (Jing et al., 2012).

Human glutathione S-transferases T1 (GSTT1) is phase II metabolizing enzyme protecting against cancer by detoxifying numerous potentially cytotoxic/genotoxic compounds, which has been implicated in the carcinogenic process in many cancers, such as lung cancer, laryngeal cancer and esophageal cancer (Acar et al., 2006; Sreeja et al., 2008; Liu et al., 2010). Polymorphisms in this gene affect the enzymatic activities and the ability to metabolize carcinogenic compounds (Nebert et al., 1999). The most common variant of GSTT1 gene is homozygous deletion (null genotype), which has been reported to be associated with gastric cancer (Hayes and Strange, 2000). However, the sparseness of data or disagreements among the reported investigations results in the available evidence weakly. To assess the effect of GSTT1 null genotype on gastric cancer risk in Asian population more precisely, we conducted most of the related studies and performed this meta-analysis of published data investigating whether the null genotype of GSTT1 gene was associated with the risk of gastric cancer.

\section{Materials and Methods}

\section{Publication search}

A literature search of PubMed, Embase, Chinese Biomedical database (CBM), Weipu database, Wanfang 
database and Chinese National Knowledge Infrastructure (CNKI) was conducted using combinations of the following keywords: "gastric cancer or gastric carcinoma or gastric neoplasm" and "polymorphism or variant or mutation" and "GSTT1 or glutathione S-transferase T1". The language was limited to Chinese and English. All studies that evaluate the relationship between polymorphisms in GSTT1 gene and gastric cancer risk were retrieved. Studies included in the meta-analysis had to meet all of the following criteria: (1) evaluation of the polymorphisms in GSTT1 gene and gastric cancer risk, (2) use of a case-control design, (3) published in a journal, (4) sufficient genotype data for estimating the odds ratio (OR) with $95 \%$ confidence intervals (CI). The exclusion criteria were: (1) abstracts and reviews, (2) studies that did not offer genotype frequency. Additionally, in studies with overlapping or repeating data, the most recent or complete studies with the largest sample size were recruited into the meta-analysis.

\section{Data extraction}

Two of the authors extracted all data independently (YZ and LCD), complied with the selection criteria, and must reach a consensus on all items. In case of conflicting evaluations, a third author (JB) assessed the articles. The following information were collected: first author's name, year of publication, country of origin, cancer type, genotyping method, mean age of case, total number of cases and controls, and genotype distributions (both null GSTT1 and non-null GSTT1) in cases and controls. The distributions of GSTT1 genotypes in subgroups (smoking status, alcohol status, Helicobacter pylori (H. pylori) infection status, and histology type) were also elicited.

\section{Statistical analysis}

Statistical analysis was conducted by using Review Manager 5.3 and STATA 12.0. The strength of association between GSTT1 null polymorphism and gastric cancer risk was assessed as OR with corresponding 95\% CI. The significance of the pooled OR was evaluated by using a Z-test and $p<0.05$ was considered statistically significant.

Heterogeneity among studies was valued by Chisquare test, which was considered significant for $p \leq 0.10$. The fixed-effects and random-effects model were used to pool the results, when $p \leq 0.10$, a random-effects model was used; when $p>0.10$, a fixed-effects model was utilized. Six subgroups were analyzed to evaluate subregion-specific, study design-specific, smoking status-specific, alcohol status-specific, $H$. pylori infection status-specific and histology type-specific effects, which were performed by subregion group (East-Asia, South-Asia, Southeast-Asia and West-Asia), study design (Hospital-based study and Population-based study), smoking status (Smoking and Non-smoking), alcohol status (Alcohol and Non-alcohol), H. pylori infection status (Infection and Non-infection), and histology type (Diffuse and Intestinal). Sensitivity analysis was conducted by sequentially excluding each study to check the stability of the result. Inverted funnel plots was utilized to provide a diagnosis of publication bias and the degree of asymmetry was tested by Egger's test ( $p<0.05$ was considered significant).

\section{Results}

Study selection and study characteristics

As shown in Figure 1, a total of 214 results relevant to the search terms in the selected databases were identified. In the first selection, 114 were included to more careful screening, 100 were excluded for not involving polymorphisms in GSTT1 gene and risk of gastric cancer. After reading the titles and abstracts, 52 articles were included for full-text view, 62 articles were excluded for not investigating the association between GSTT1 and gastric cancer in Asians. 13 articles were excluded after reading the full text. Six were not Asians studies (Gonzalez et al., 2004; Martinez et al., 2006; Ruzzo et al., 2007; Wideroff et al., 2007; Zendehdel et al., 2009; Garcia-Gonzalez et al., 2012), and seven were repeating or overlapping publications (Cai et al., 1999; Setiawan et al., 2001; Gao et al., 2002b; Qian et al., 2003; Sheng et al., 2004; Nan et al., 2005b; Tripathi et al., 2008). Finally, 39 articles that report on the effects of GSTT1 polymorphisms on gastric cancer in Asia covering in total of 7,737 gastric cancer cases and 10,823 controls were remained for data extraction. 11 of them were Chinese (Qian et al., 2001; Sheng and Wang, 2002; Zheng et al., 2002; Liu et al., 2003; Ye et al., 2003; Zhang et al., 2003; Zhou et al., 2003; Xie et al., 2008; Feng et al., 2010; Liu et al., 2013; Shi et al., 2014), and 28 were English (Katoh et al., 1996; Setiawan et al., 2000; Cai et al., 2001; Saadat and Saadat, 2001; Gao et al., 2002a; Wu et al., 2002; Choi et al., 2003; Roth et al., 2004; Mu et al., 2005; Nan et al., 2005a; Sheng et al., 2005; Tamer et al., 2005; Hong et al., 2006; Al-Moundhri et al., 2009; Malik et al., 2009; Masoudi et al., 2009; Moy et al., 2009; Piao et al., 2009; Nguyen et al., 2010; Yadav et al., 2010; Luo et al., 2011; Tripathi et al., 2011; Yadav et al., 2011; Zhang et al., 2011; Jing et al., 2012; Malakar et al., 2012; Eom et al., 2013; Haholu et al., 2013). The characteristics of included studies were summarized in Table 1. The distribution of GSTT1 genotypes in the subgroups were shown in Table 2 .

\section{Meta-analysis results}

The heterogeneity was analyzed for all 39 studies and the value of Chi-square test was 65.85 with 38 degrees of freedom and $p=0.003$ in a random-effects model. Overall,

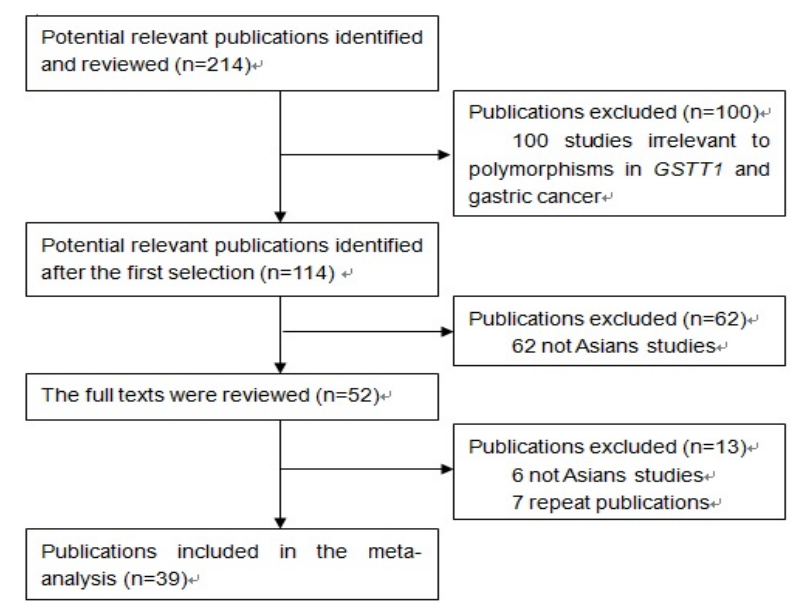

Figure 1. Flow Biagram for Selection of Studies 


\begin{tabular}{|c|c|c|c|c|c|c|c|c|c|c|c|}
\hline \multirow{3}{*}{ Study } & \multirow{3}{*}{ Country } & \multirow{3}{*}{ Subregion } & \multirow{3}{*}{$\begin{array}{l}\text { Cancer } \\
\text { type }\end{array}$} & \multirow{3}{*}{$\begin{array}{l}\text { Study } \\
\text { design }\end{array}$} & \multirow{3}{*}{$\begin{array}{l}\text { Sample } \\
\text { size (case/ } \\
\text { control) }\end{array}$} & \multicolumn{4}{|c|}{$\begin{array}{c}\text { Genotype frequency of } \\
\text { GSTT1 }\end{array}$} & \multirow{3}{*}{$\begin{array}{l}\text { Case } \\
\text { age } \\
\text { (year) }\end{array}$} & \multirow{3}{*}{$\begin{array}{l}\text { Genotyping } \\
\text { method }\end{array}$} \\
\hline & & & & & & \multicolumn{2}{|c|}{ Case } & \multicolumn{2}{|c|}{ Control } & & \\
\hline & & & & & & Null & $\begin{array}{l}\text { Non- } \\
\text { Null }\end{array}$ & Null & $\begin{array}{l}\text { Non- } \\
\text { Null }\end{array}$ & & \\
\hline $\begin{array}{l}\text { Al-Moundhri } \\
2009\end{array}$ & Oman & West-Asia & GC & PB & $107 / 107$ & 19 & 88 & 20 & 87 & NA & Multiplex-PCR \\
\hline Cai 2001 & China & East-Asia & GC & PB & $95 / 94$ & 41 & 54 & 47 & 47 & 59 & PCR \\
\hline Choi 2003 & Korea & East-Asia & GAC & HB & $80 / 177$ & 43 & 37 & 94 & 83 & NA & PCR \\
\hline Eom 2013 & Korea & East-Asia & GC & $\mathrm{HB}$ & $477 / 477$ & 210 & 267 & 211 & 265 & 57.8 & Multiplex-PCR \\
\hline Feng 2010 & China & East-Asia & GC & HB & $585 / 585$ & 259 & 326 & 247 & 338 & 61.7 & PCR \\
\hline Gao 2002 & China & East-Asia & GC & PB & $153 / 223$ & 71 & 82 & 119 & 104 & 60.8 & Multiplex-PCR \\
\hline Haholu 2013 & Turkey & West-Asia & GC & HB & $50 / 57$ & 10 & 40 & 16 & 41 & NA & Duplex-PCR \\
\hline Hong 2006 & Korea & East-Asia & GAC & PB & $108 / 238$ & 45 & 63 & 119 & 119 & 62 & Multiplex-PCR \\
\hline Jing 2012 & China & East-Asia & GC & HB & $410 / 410$ & 236 & 174 & 202 & 208 & 49.5 & PCR-CTPP \\
\hline Katoh 1996 & Japan & East-Asia & GAC & PB & $139 / 126$ & 66 & 73 & 56 & 70 & 62 & Multiplex-PCR \\
\hline Liu 2003 & China & East-Asia & GAC & HB & $127 / 114$ & 76 & 51 & 55 & 59 & 55 & Multiplex-PCR \\
\hline Liu 2013 & China & East-Asia & GC & PB & $110 / 220$ & 49 & 61 & 73 & 147 & 56.2 & PCR \\
\hline Luo 2011 & China & East-Asia & GC & PB & $123 / 129$ & 77 & 46 & 63 & 66 & 55.2 & PCR-RFLP \\
\hline Malakar 2012 & India & South-Asia & GC & PB & $102 / 204$ & 37 & 65 & 93 & 111 & NA & PCR \\
\hline Malik 2009 & India & South-Asia & GC & PB & $108 / 195$ & 33 & 75 & 49 & 146 & 55.9 & Multiplex-PCR \\
\hline Masoudi 2009 & Iran & West-Asia & GC & HB & $92 / 134$ & 50 & 42 & 38 & 96 & 57.7 & PCR \\
\hline Moy 2009 & China & East-Asia & GC & PB & $170 / 735$ & 97 & 73 & 415 & 320 & 58.2 & TaqMan-PCR \\
\hline Mu 2005 & China & East-Asia & GC & PB & $196 / 393$ & 93 & 103 & 192 & 201 & NA & PCR-RFLP \\
\hline Nan 2005 & Korea & East-Asia & GC & HB & $400 / 614$ & 171 & 229 & 247 & 367 & 60 & Multiplex-PCR \\
\hline Nguyen 2010 & Vietnam & $\begin{array}{l}\text { Southeast- } \\
\text { Asia }\end{array}$ & G & HB & 0 & 25 & 34 & 38 & 62 & 62.8 & Multilex-PCR \\
\hline Piao 2009 & Korea & East-Asia & GC & PB & $2212 / 1699$ & 1172 & 1041 & 858 & 841 & 60.2 & TaqMan-PCR \\
\hline Qian 2001 & China & East-Asia & GC & PB & $89 / 94$ & 51 & 38 & 46 & 48 & 62 & PCR \\
\hline Roth 2004 & China & East-Asia & GC & PB & $90 / 454$ & 43 & 47 & 243 & 211 & 60.4 & TaqMan-PCR \\
\hline Saadat 2001 & Iran & West-Asia & GC & NA & $42 / 131$ & 15 & 27 & 41 & 90 & NA & PCR \\
\hline Setiawan 2000 & China & East-Asia & GAC & PB & $73 / 417$ & 44 & 37 & 190 & 228 & NA & PCR-RFLP \\
\hline Sheng 2002 & China & East-Asia & GC & PB & $110 / 675$ & 43 & 67 & 309 & 366 & 59.3 & PCR-RFLP \\
\hline Sheng 2005 & China & East-Asia & GAC & PB & $121 / 121$ & 64 & 57 & 54 & 67 & 59.7 & PCR \\
\hline Shi 2014 & China & East-Asia & GC & PB & $60 / 83$ & 34 & 26 & 33 & 50 & 55.6 & Multiplex-PCR \\
\hline Tamer 2005 & Turkey & West-Asia & GC & PB & $70 / 204$ & 21 & 49 & 53 & 151 & 57.7 & Real-time PCR \\
\hline Tripathi 2011 & India & South-Asia & GC & NA & $82 / 89$ & 29 & 53 & 19 & 70 & 54.3 & PCR \\
\hline Wu 2002 & China & East-Asia & GAC & HB & $356 / 278$ & 181 & 175 & 130 & 148 & 62 & Multiplex-PCR \\
\hline Xie 2008 & China & East-Asia & GAC & $\mathrm{HB}$ & $70 / 100$ & 48 & 22 & 50 & 50 & 56.6 & PCR \\
\hline Yadav 2010 & India & South-Asia & GAC & PB & $133 / 270$ & 50 & 83 & 85 & 185 & NA & Multiplex-PCR \\
\hline Yadav 2011 & India & South-Asia & GC & PB & $41 / 130$ & 6 & 35 & 14 & 116 & 51.9 & Multiplex-PCR \\
\hline Ye 2003 & China & East-Asia & GAC & HB & $56 / 56$ & 34 & 22 & 26 & 30 & 57.6 & Multiplex-PCR \\
\hline Zhang 2003 & China & East-Asia & GAC & HB & $127 / 114$ & 76 & 51 & 55 & 59 & 55 & Multiplex-PCR \\
\hline Zhang 2011 & China & East-Asia & GC & HB & $194 / 412$ & 114 & 80 & 198 & 214 & 46.4 & PCR \\
\hline Zheng 2002 & China & East-Asia & GC & PB & $92 / 92$ & 49 & 43 & 38 & 54 & 53.2 & PCR \\
\hline Zhou 2003 & China & East-Asia & GAC & HB & $19 / 72$ & 10 & 9 & 28 & 44 & 54.5 & Multiplex-PCR \\
\hline
\end{tabular}

GC, gastric cancer; GAC, gastric adenocarcinoma; HB, hospital-based study; PB, population-based study; NA, not available; PCR, polymerase chain reaction; RFLP-PCR, polymerase chain reaction-restriction fragment length polymorphism; Multiplex-PCR, multiplex polymerase chain reaction; Null, null genotype in GSTT1; Non-null, non-null genotype in GSTT1

there was statistical evidence of an association between the null genotype of GSTT1 and gastric cancer risk. OR was $1.19(95 \% \mathrm{CI}=1.08-1.31)$ and the test for overall effect $\mathrm{Z}$ value was $3.68(p=0.0002)$. The results suggested that null genotype in GSTT1 have an increased risk of gastric cancer (Figure 2).

In subgroup analysis by subregion, there was a significant association between GSTT1 null genotype and gastric cancer in East-Asia population $(\mathrm{OR}=1.16,95 \%$ $\mathrm{CI}=1.06-1.27, p=0.002$ ), but no significant association was found in South-Asia population $(\mathrm{OR}=1.21,95 \% \mathrm{CI}=0.84$ $1.75, p=0.3)$, Southeast-Asia population ( $\mathrm{OR}=1.20$, 95\% $\mathrm{CI}=0.62-2.31, p=0.59)$ and West-Asia population $(\mathrm{OR}=1.28,95 \% \mathrm{CI}=0.76-2.16, p=0.35)$ (Figure 3). In 
Table 2. The Frequency Distributions of the GSTT1 Genotypes in the Subgroups

\begin{tabular}{|c|c|c|c|c|c|c|c|c|c|}
\hline & \multirow{3}{*}{ Study } & \multicolumn{4}{|c|}{ Yes } & \multicolumn{4}{|c|}{ No } \\
\hline & & \multicolumn{2}{|c|}{ Case } & \multicolumn{2}{|c|}{ Control } & \multicolumn{2}{|c|}{ Case } & \multicolumn{2}{|c|}{ Control } \\
\hline & & null & non-null & null & non-null & null & non-null & null & non-null \\
\hline \multirow{6}{*}{ Smoking ${ }^{\mathrm{a}}$} & Gao 2002 & 61 & 62 & 67 & 60 & 10 & 20 & 52 & 44 \\
\hline & Hong 2006 & 26 & 34 & 54 & 50 & 19 & 29 & 64 & 70 \\
\hline & Malakar 2012 & 27 & 54 & 56 & 74 & 10 & 11 & 37 & 45 \\
\hline & Setiawan 2000 & 23 & 19 & 63 & 82 & 21 & 18 & 127 & 146 \\
\hline & Shi 2014 & 29 & 10 & 11 & 18 & 5 & 16 & 22 & 32 \\
\hline & Tamer 2005 & 10 & 24 & 18 & 66 & 11 & 25 & 35 & 85 \\
\hline \multirow{3}{*}{ Alcohol $^{\mathrm{b}}$} & Gao 2002 & 28 & 29 & 25 & 28 & 43 & 53 & 94 & 76 \\
\hline & Hong 2006 & 15 & 27 & 52 & 40 & 30 & 36 & 68 & 78 \\
\hline & Setiawan 2000 & 14 & 13 & 65 & 70 & 30 & 24 & 125 & 158 \\
\hline \multirow{3}{*}{$\begin{array}{l}\text { H.pyloric } \\
\text { infection }\end{array}$} & Hong 2006 & 29 & 42 & 61 & 69 & 15 & 22 & 57 & 51 \\
\hline & Setiawan 2000 & 25 & 21 & 121 & 128 & 14 & 9 & 59 & 85 \\
\hline & Tripathi 2011 & 21 & 30 & 14 & 51 & 8 & 23 & 5 & 19 \\
\hline \multirow{4}{*}{ Histology $y^{d}$} & Choi 2003 & 12 & 16 & 94 & 83 & 31 & 21 & 94 & 83 \\
\hline & Hong 2006 & 19 & 31 & 119 & 119 & 15 & 20 & 119 & 119 \\
\hline & Liu 2003 & 28 & 23 & 55 & 59 & 48 & 28 & 55 & 59 \\
\hline & Zhang 2003 & 28 & 23 & 55 & 59 & 48 & 38 & 55 & 59 \\
\hline
\end{tabular}

${ }^{\mathrm{a}}$ Yes, smoking status; No, no-smoking status; ${ }^{\mathrm{b}}$ Yes, alcohol status; No, no-alcohol status; ${ }^{\mathrm{c}}$ Yes, infection status; No, no-infection status; ${ }^{\mathrm{d}}$ Yes, diffuse histology; No, intestinal histology.

Table 3. The Results of Pooled Odds Ratio (OR) with $95 \%$ Confidence Interval (CI) in the Meta-analysis

\begin{tabular}{|c|c|c|c|c|c|c|}
\hline & \multirow[t]{2}{*}{$\mathrm{N}$} & \multirow{2}{*}{$\frac{\text { Sample size }}{\text { (case/control) }}$} & \multirow{2}{*}{$\begin{array}{c}\text { Analysis } \\
\text { model }\end{array}$} & \multicolumn{2}{|c|}{ Test of association } & \multirow{2}{*}{$\begin{array}{c}\begin{array}{c}\text { Test for } \\
\text { heterogeneity }\end{array} \\
p^{b}\end{array}$} \\
\hline & & & & OR $(95 \%$ CI $)$ & $p^{a}$ & \\
\hline Total & 39 & $7737 / 10823$ & $\mathrm{R}$ & $1.19[1.08,1.31]$ & 0.0002 & 0.003 \\
\hline \multicolumn{7}{|l|}{ Subregion } \\
\hline East-Asia & 28 & $6851 / 9202$ & $\mathrm{R}$ & $1.16[1.06,1.27]$ & 0.002 & 0.02 \\
\hline South-Asia & 5 & $466 / 888$ & $\mathrm{R}$ & $1.21[0.84,1.75]$ & 0.3 & 0.1 \\
\hline Southeast-Asia & 1 & $59 / 100$ & $\mathrm{R}$ & $1.20[0.62,2.31]$ & 0.59 & NA \\
\hline West-Asia & 5 & $361 / 633$ & $\mathrm{R}$ & $1.28[0.76,2.16]$ & 0.35 & 0.02 \\
\hline \multicolumn{7}{|l|}{ Study design } \\
\hline PB & 22 & $4511 / 6904$ & $\mathrm{R}$ & $1.09[0.97,1.23]$ & 0.16 & 0.05 \\
\hline HB & 15 & $3226 / 3919$ & $\mathrm{R}$ & $1.32[1.14,1.52]$ & 0.0003 & 0.03 \\
\hline \multicolumn{7}{|l|}{ Smoking status } \\
\hline Smoking & 6 & $379 / 619$ & $\mathrm{R}$ & $1.03[0.79,1.34]$ & 0.83 & 0.01 \\
\hline Non-smoking & 6 & $195 / 759$ & $\mathrm{~F}$ & $0.83[0.60,1.15]$ & 0.25 & 0.28 \\
\hline \multicolumn{7}{|l|}{ Alcohol status } \\
\hline Alcohol & 3 & $126 / 280$ & $\mathrm{~F}$ & $0.79[0.51,1.23]$ & 0.3 & 0.13 \\
\hline Non-alcohol & 3 & $216 / 599$ & $\mathrm{~F}$ & $0.95[0.70,1.31]$ & 0.77 & 0.08 \\
\hline \multicolumn{7}{|l|}{ H. pylori infection } \\
\hline Infection & 3 & $168 / 444$ & $\mathrm{R}$ & $1.29[0.68,2.44]$ & 0.43 & 0.07 \\
\hline Non-infection & 3 & $91 / 276$ & $\mathrm{R}$ & $1.17[0.50,2.75]$ & 0.72 & 0.09 \\
\hline \multicolumn{7}{|l|}{ Histology type } \\
\hline Diffuse & 4 & $180 / 643$ & $\mathrm{~F}$ & $0.92[0.66,1.29]$ & 0.64 & 0.22 \\
\hline Intestinal & 4 & $249 / 643$ & $\mathrm{~F}$ & $1.30[0.96,1.77]$ & 0.09 & 0.31 \\
\hline
\end{tabular}

Bold values are statistically significant; N, number of studies; OR, odds ratio; CI, confidence interval; F, fixed-effect model; R, random-effect model; H. pylori, Helicobacter pylori; NA, not applicable; ${ }^{\mathrm{a}} p$, value for Z-test; ${ }^{\mathrm{b}} p$, value for Chi-square test

subgroup analysis of study design, for population-based study $(\mathrm{OR}=1.09,95 \% \mathrm{CI}=0.97-1.23, p=0.16)$, for hospitalbased study $(\mathrm{OR}=1.32,95 \% \mathrm{CI}=1.14-1.52, p=0.0003)$ (Figure 4). Additionally, no significant associations were found between GSTT1 null genotype and gastric cancer both in the subgroup analysis of smoking status (Smoking, $\mathrm{OR}=1.03,95 \% \mathrm{CI}=0.79-1.34, p=0.83$; Non-smoking, $\mathrm{OR}=0.83,95 \% \mathrm{CI}=0.60-1.15, p=0.25)$, alcohol status (Alcohol, $\mathrm{OR}=0.79,95 \% \mathrm{CI}=0.51-1.23, p=0.3$; Nonalcohol, $\mathrm{OR}=0.95,95 \% \mathrm{CI}=0.7-1.13, p=0.77), \mathrm{H}$. pylori 


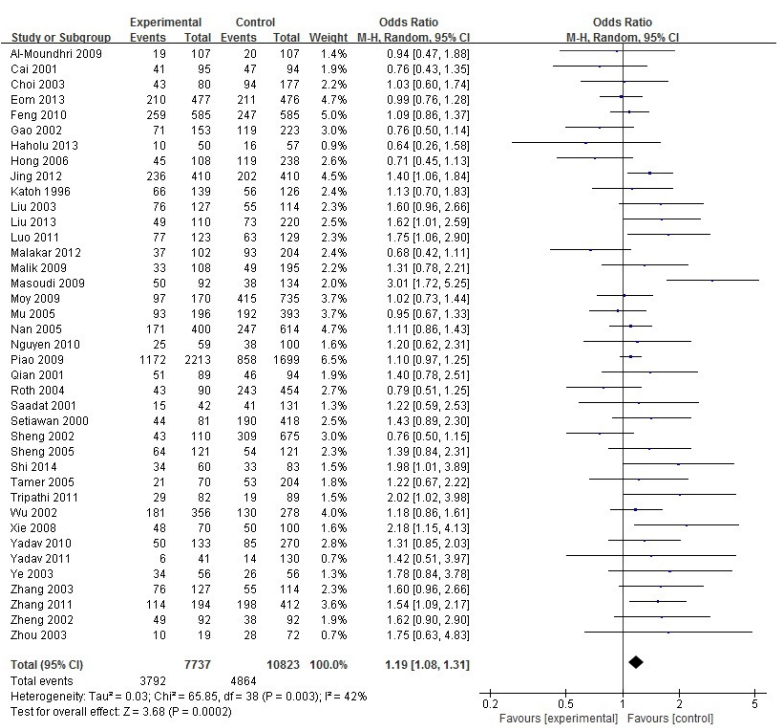

Figure 2. Forest Plots for the Association Between Null Genotype of GSTT1 and Gastric Cancer Risk. Boxes represent the ORs of individual studies, and diamonds represent the overall OR. Horizontal lines represent the $95 \%$ CI

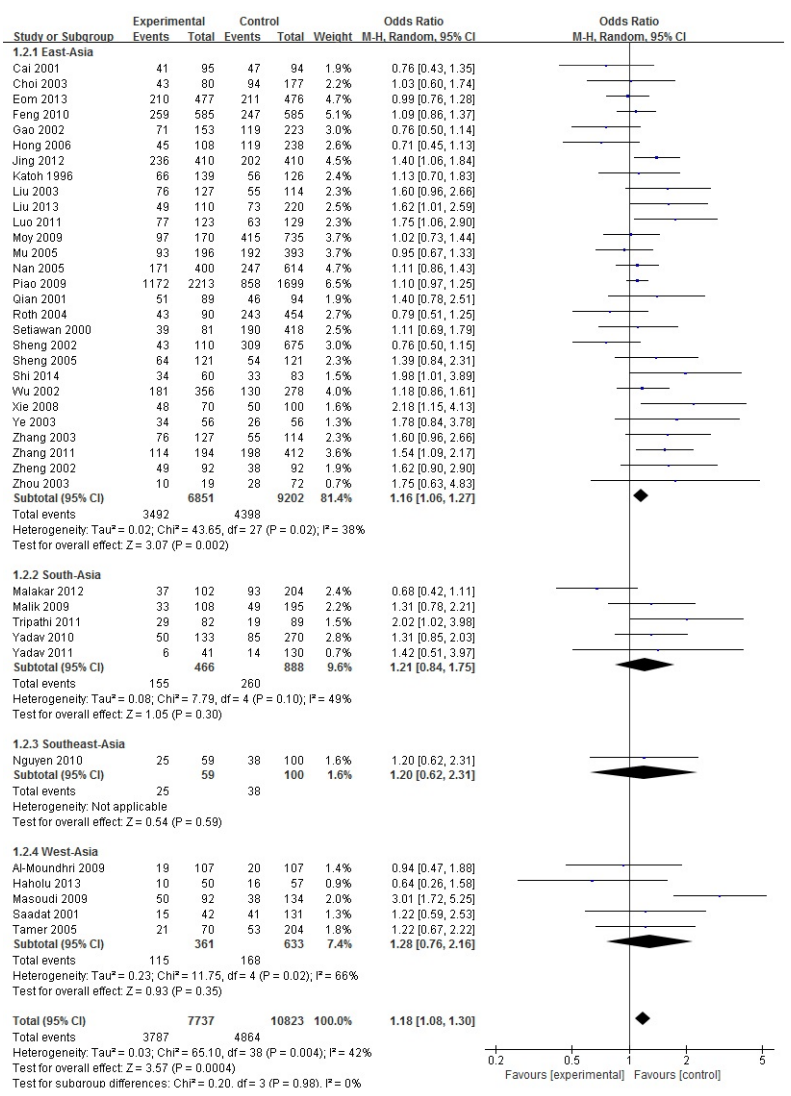

Figure 3. Forest Plots for the Subgroup Analysis by Subregion in the Meta-analysis
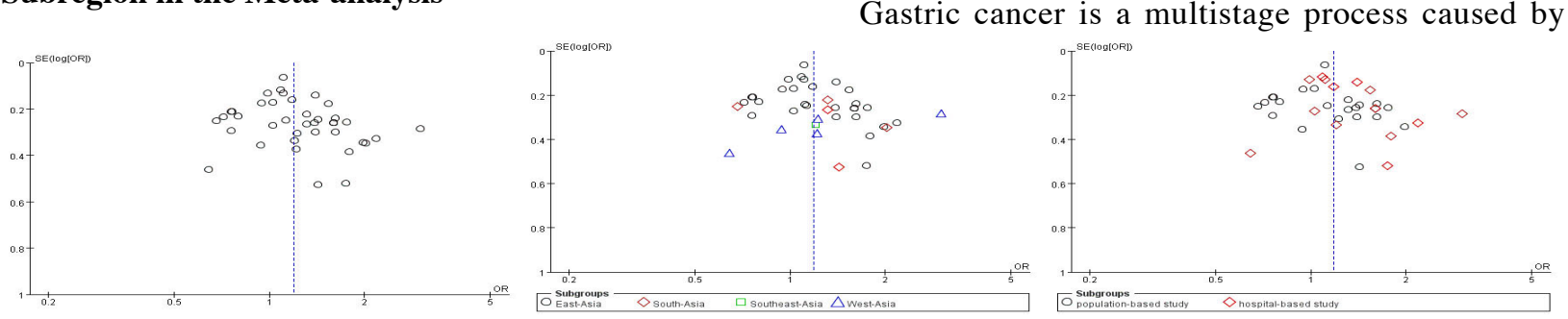

Figure 5. Inverted Funnel Plot for Publication Bias in Selection of Studies on Null Genotype of GSTT1. A overall, B subgroup analysis by subregion, $\mathrm{C}$ subgroup analysis by study design 
multifarious factors that environmental and genetic factors may all contribute to the etiology of this carcinoma (Al-Moundhri et al., 2009). The relationship between polymorphisms in genes which encode proteins involving in carcinogens metabolism and individual susceptibility to carcinogenic impacts of the specific chemical compound is a new and concern field of research. GSTT1 is one class of glutathione S-transferases (GSTs)one type of biotransformation enzymes, which is appear in most epithelial tissues of the human gastrointestinal tract. The presumptive function of GSTT1 is to protect tissues resist toxic or carcinogenic compounds that may enter to human body through the digestive tract or respiratory system (Qian et al., 2001). At present, the association between the GSTT1 genetic polymorphisms and susceptibility to gastric cancer has been conflicting. Accordingly, we performed a meta-analysis, a quantitative research method increasing sample size and statistical significance, to estimate whether null genotype in GSTT1 gene associated with gastric cancer risk. Finally, we conducted 39 published studies including 7737 cases and 10823 controls, which met the inclusion criteria for the meta-analyses. In overall combination studies, the results indicated that null polymorphism of GSTT1 is associated with a significant increase in the risk of gastric cancer. In the subgroup analysis by subregion, the GSTT1 null genotype was associated with an increased risk of gastric cancer in East Asian population but not in South Asian, Southeast Asian and West Asian population, which consistent with the statistical result performed by Jemal in 2011 (Jemal et al., 2011). Possible explanation to these different results may be that different genetic backgrounds and environmental exposures might play a key role in the development of gastric cancer. Furthermore, significantly increased gastric cancer risk was found in hospital-based design but not in population-based design. Such result may due to the biases in hospital-based design, the genotype distributions in hospital-based design could not represent the general population very well. In the subgroup analysis of smoking status and alcohol status, it is worthy to mention the inconsonant results which differ with a previous meta-analysis performed by Wang et al (Wang et al., 2014). In Wang's study, GSTT1 null genotype has a significantly increased gastric cancer risk among smokers and alcohol drinkers. Inversely, results of our study indicated the lack of association between GSTT1 null genotype and gastric cancer among smoker and alcohol drinker. The controversial results might due to the huge difference in simple size mainly. The other explanation to these different results may be that the difference or uniform definition of smoking and alcohol drinking in each study suggesting uncertain influence among smoker and alcohol drinker. Previous study suggested that $H$. pylori infection plays a central role in the gastric cancer carcinogenesis (Trajkov et al., 2007). Although H. pylori infection is independent risk factor for gastric cancer, there was no evidence to suggest an interaction between GSTT1 null polymorphism and this risk factor in the present study. Possible explanation to such result may be the limitation of studies because studies with small sample had insufficient statistical power to detect a slight effect.
In this meta-analysis, only three studies involving 259 cases and 720 controls examined the interaction of the GSTT1 null genotype and the H.pylori infection status in gastric cancer patients. Considering the limited studies, our result should be interpreted with caution. Therefore, more relevant data are needed to confirm this finding.

Some issues which may affect the results should be addressed when performing meta-analysis, such as heterogeneity, sensitivity analysis and publication bias. In our study, heterogeneity existed in overall comparisons. After carrying out sensitivity analysis by sequentially excluding individual studies, we found that the results of our meta-analysis are stable. Hence a random effect model was performed to pooling data. Publication bias is another important issue that may influence the results of meta-analysis, which also be discussed in the present study. In this meta-analysis, both examination results of Inverted funnel plot and Egger's test were indicated that there was no risk of publication bias in this meta-analysis (Inverted funnel plot seemed approximately symmetrical and $p=0.675$ for Egger's test).

To our knowledge, there was a recently published study by Zhang in 2013 (Zhang et al., 2013). They also focus on the correlation of GSTT1 genetic polymorphisms with gastric cancer risk in the Asian population. But there are differences between these two studies. First, the present meta-analysis updates the recent data for this polymorphism and gastric cancer risk and includes more studies than Zhang's study, which possibly providing more reliable conclusions; Second, more subgroups of metaanalysis were addressed in our study, such as subregion group, smoking status, alcohol status, H. pylori infection status and histology type. Although these differences, our study also indicated the null genotype of GSTT1 might contribute to the risk of gastric cancer, which is consistent with Zhang's study results.

In summary, the present meta-analysis suggested that null variant in the GSTT1 gene may contribute to gastric cancer risk. However, we have to mention several limitations of this study. First, a literature search just carried out in the selected databases; second, only published studies in Chinese and English were included for data analysis. For these reasons, some potential studies included by other databases or published in other languages or unpublished could be missed. In addition, due to lack of available data, the possible interaction of gene-environment could not be evaluated accurately. Accordingly, larger well-designed studies are warranted to verify these results. Moreover, gastric cancer carcinogenesis undergoes a complex progression from the development of chronic inflammation to acute neoplasias (Macarthur et al., 2004). Thus, further studies investigating GSTT1 polymorphisms for gastritis should be performed.

\section{References}

Acar H, Ozturk K, Muslumanoglu MH, et al (2006). Relation of glutathione S-transferase genotypes (GSTM1 and GSTT1) to laryngeal squamous cell carcinoma risk. Cancer Genet Cytogenet, 169, 89-93. 
The GSTT1 Polymorphism and Gastric Cancer Risk: a Meta-analysis in Asia

Al-Moundhri MS, Alkindy M, Al-Nabhani M, et al (2009). Combined polymorphism analysis of glutathione S-transferase M1/G1 and interleukin-1B (IL-1B)/interleukin 1-receptor antagonist (IL-1RN) and gastric cancer risk in an Omani Arab Population. J Clin Gastroenterol, 43, 152-6.

Cai L, Yu SZ, Chen J, S. (1999). Relationship between Glutathione S-Transferase M1, T1 Genotype and Susceptibility to Gastric Cancer. Chinese J Prev Med, 6, 331-333.

Cai L, Yu SZ, Zhang ZF (2001). Glutathione S-transferases M1, $\mathrm{T} 1$ genotypes and the risk of gastric cancer: a case-control study. World J Gastroenterol, 7, 506-9.

Choi SC, Yun KJ, Kim TH, et al (2003). Prognostic potential of glutathione S-transferase M1 and T1 null genotypes for gastric cancer progression. Cancer Lett, 195, 169-75.

Eom SY, Yim DH, Zhang Y, et al (2013). Dietary aflatoxin B1 intake, genetic polymorphisms of CYP1A2, CYP2E1, EPHX1, GSTM1, and GSTT1, and gastric cancer risk in Korean. Cancer Causes Control, 24, 1963-72.

Feng JY, Sheng XB, Yan YY (2010). Multi-gene risk analysis of susceptibility genes on primary gastric cancer. Chinese $J$ Public Health, 6, 688-9.

Gao CM, Takezaki T, Wu JZ, et al (2002a). Glutathione-Stransferases M1 (GSTM1) and GSTT1 genotype, smoking, consumption of alcohol and tea and risk of esophageal and stomach cancers: a case-control study of a high-incidence area in Jiangsu Province, China. Cancer Lett, 188, 95-102.

Gao CM, Toshiro T, Wu JZ, et al (2002b). Effects of GSTT 1 and GSTM1 Genotypes, Lifestyle e Factors and Their Interactions on Risk of Esophageal and Stomach Cancers. China J Cancer Prev Treat, 2, 113-7.

Garcia-Gonzalez MA, Quintero E, Bujanda L, et al (2012). Relevance of GSTM1, GSTT1, and GSTP1 gene polymorphisms to gastric cancer susceptibility and phenotype. Mutagenesis, 27, 771-7.

Gonzalez A, Ramirez V, Cuenca $P$, et al (2004). [Polymorphisms in detoxification genes CYP1A1, CYP2E1, GSTT1 and GSTM1 in gastric cancer susceptibility]. Rev Biol Trop, 52, 591-600.

Haholu A, Berber U, Karagoz B, et al (2013). Is there any association of glutathione S-transferase T1 (GSTT1) and glutathione S-transferase M1 (GSTM1) gene polymorphism with gastric cancers? Pol J Pathol, 64, 247-52.

Hayes JD, Strange RC (2000). Glutathione S-transferase polymorphisms and their biological consequences. Pharmacol, 61, 154-66.

Hong SH, Kim JW, Kim HG, et al (2006). [Glutathione S-transferases (GSTM1, GSTT1 and GSTP1) and $\mathrm{N}$-acetyltransferase 2 polymorphisms and the risk of gastric cancer]. J Prev Med Public Health, 39, 135-40.

Jemal A, Bray F, Center MM, et al (2011). Global cancer statistics. CA Cancer J Clin, 61, 69-90.

Jing C, Huang ZJ, Duan YQ, et al (2012). Glulathione-Stransferases gene polymorphism in prediction of gastric cancer risk by smoking and Helicobacter pylori infection status. Asian Pac J Cancer Prev, 13, 3325-8.

Kanavos $P$ (2006). The rising burden of cancer in the developing world. Ann Oncol, 17, 15-23.

Katoh T, Nagata N, Kuroda Y, et al (1996). Glutathione S-transferase M1 (GSTM1) and T1 (GSTT1) genetic polymorphism and susceptibility to gastric and colorectal adenocarcinoma. Carcinogenesis, 17, 1855-9.

Liu J, Zhang WY, Wei Y (2003). GSTM1 and GSTT1 genetic polymorphisms and helicobacter pylori infection in gastric adenocarcinoma. J Mathematical Med, 1, 26-8.

Liu L, Zhang D, Fan H (2013). GSTT1, GSTP1 gene polymorphism and genetic susceptibility to Nigeria hui cardiac cancer research. J Ningxiao Medical University.
Liu R, Yin L, Pu Y, et al (2010). Functional alterations in the glutathione $\mathrm{S}$-transferase family associated with enhanced occurrence of esophageal carcinoma in China. $J$ Toxicol Environ Health A, 73, 471-82.

Luo YP, Chen HC, Khan MA, et al (2011). Genetic polymorphisms of metabolic enzymes-CYP1A1, CYP2D6, GSTM1, and GSTT1, and gastric carcinoma susceptibility. Tumour Biol, 32, 215-22.

Macarthur M, Hold GL, El-Omar EM (2004). Inflammation and Cancer II. Role of chronic inflammation and cytokine gene polymorphisms in the pathogenesis of gastrointestinal malignancy. Am J Physiol Gastrointest Liver Physiol, 286, 515-20.

Malakar M, Devi KR, Phukan RK, et al (2012). Genetic polymorphism of glutathione S-transferases M1 and T1, tobacco habits and risk of stomach cancer in Mizoram, India. Asian Pac J Cancer Prev, 13, 4725-32.

Malik MA, Upadhyay R, Mittal RD, et al (2009). Role of xenobiotic-metabolizing enzyme gene polymorphisms and interactions with environmental factors in susceptibility to gastric cancer in Kashmir Valley. $J$ Gastrointest Cancer, 40, 26-32.

Martinez C, Martin F, Fernandez JM, et al (2006). Glutathione S-transferases mu 1, theta 1 , pi 1 , alpha 1 and mu 3 genetic polymorphisms and the risk of colorectal and gastric cancers in humans. Pharmacogenomics, 7, 711-8.

Masoudi M, Saadat I, Omidvari S, et al (2009). Genetic polymorphisms of GSTO2, GSTM1, and GSTT1 and risk of gastric cancer. Mol Biol Rep, 36, 781-4.

Moy KA, Yuan JM, Chung FL, et al (2009). Isothiocyanates, glutathione S-transferase M1 and T1 polymorphisms and gastric cancer risk: a prospective study of men in Shanghai, China. Int J Cancer, 125, 2652-9.

Mu LN, Lu QY, Yu SZ, et al (2005). Green tea drinking and multigenetic index on the risk of stomach cancer in a Chinese population. Int J Cancer, 116, 972-83.

Nan HM, Park JW, Song YJ, et al (2005a). Kimchi and soybean pastes are risk factors of gastric cancer. World $J$ Gastroenterol, 11, 3175-81.

Nan HM, Song YJ, Yun HY, et al (2005b). Effects of dietary intake and genetic factors on hypermethylation of the hMLH1 gene promoter in gastric cancer. World $J$ Gastroenterol, 11, 3834-41.

Nebert DW, Ingelman-Sundberg M, Daly AK (1999). Genetic epidemiology of environmental toxicity and cancer susceptibility: human allelic polymorphisms in drugmetabolizing enzyme genes, their functional importance, and nomenclature issues. Drug Metab Rev, 31, 467-87.

Nguyen TV, Janssen MJ, van Oijen MG, et al (2010). Genetic polymorphisms in GSTA1, GSTP1, GSTT1, and GSTM1 and gastric cancer risk in a Vietnamese population. Oncol Res, 18, 349-55.

Piao JM, Shin MH, Kweon SS, et al (2009). Glutathione-Stransferase (GSTM1, GSTT1) and the risk of gastrointestinal cancer in a Korean population. World J Gastroenterol, 15, 5716-21.

Qian Y, Xu YC, Sheng HB (2001). A molecular epidemiological study on the relationship between glutathione s-transferase $\mathrm{m} 1$, $\mathrm{t} 1$ genetic polymorphism and susceptibility to gastric cancer. China Public Health, 2, 101-3.

Qian Y, Xu YC, Sheng HB (2003). Relationship Between CYP2E1, GSTT1 Genetic Polymorphisms and S usceptibility to Gas tric Cancer. Chin J Prev Contr Chron Non-commun Dis, 3, 107-9.

Roth MJ, Abnet CC, Johnson LL, et al (2004). Polymorphic variation of Cyp1A1 is associated with the risk of gastric cardia cancer: a prospective case-cohort study of cytochrome 
Yan Zeng et al

$P-4501 \mathrm{~A} 1$ and GST enzymes. Cancer Causes Control, 15, 1077-83.

Ruzzo A, Canestrari E, Maltese P, et al (2007). Polymorphisms in genes involved in DNA repair and metabolism of xenobiotics in individual susceptibility to sporadic diffuse gastric cancer. Clin Chem Lab Med, 45, 822-8.

Saadat I, Saadat M (2001). Glutathione S-transferase M1 and T1 null genotypes and the risk of gastric and colorectal cancers. Cancer Lett, 169, 21-6.

Setiawan VW, Zhang ZF, Yu GP, et al (2000). GSTT1 and GSTM1 null genotypes and the risk of gastric cancer: a casecontrol study in a Chinese population. Cancer Epidemiol Biomarkers Prev, 9, 73-80.

Setiawan VW, Zhang ZF, Yu GP, et al (2001). GSTP1 polymorphisms and gastric cancer in a high-risk Chinese population. Cancer Causes Control, 12, 673-81.

Shen J, Wang RT (2002). Case-control study of the polymorphisms of phaseI and phaseII metabolic genes and stomach cancer susceptibility. Tumor Jan, 1, 9-12.

Shen XB, Pu YP, Zhang J (2005). Influence of GSTT1 and GSTM1 genotypes and smoking, alcohol exposure on the occurrence of gastric cancer: case-control study from Nanjing, China. J Environ Occup Med, 4, 325-9.

Shen XB, Zhang J, Zhu LJ (2004). Relationship between glutathione S- transferase M1, T1 genetic polymorphisms, smoking and alcohol consumption and susceptibility and stomach cancer. School Public Health, 4, 2010-4.

Shi JQ, Luo BJ, Liu RY (2014). Relationship of GSTT1 gene polymorphism and smoking on the susceptibility to gastric cancer. China Medical Herald, 2, 63-66.

Sreeja L, Syamala V, Hariharan S, et al (2008). Glutathione S-transferase M1, T1 and P1 polymorphisms: susceptibility and outcome in lung cancer patients. J Exp Ther Oncol, 7, 73-85.

Tamer L, Ates NA, Ates C, et al (2005). Glutathione S-transferase M1, T1 and P1 genetic polymorphisms, cigarette smoking and gastric cancer risk. Cell Biochem Funct, 23, 267-72.

Trajkov D, Stardelova K, Dimitrova M, et al (2007). Helicobacter pylori and gastric carcinoma. Prilozi, 28, 39-46.

Tripathi S, Ghoshal U, Ghoshal UC, et al (2008). Gastric carcinogenesis: Possible role of polymorphisms of GSTM1, GSTT1, and GSTP1 genes. Scand J Gastroenterol, 43, 431-9.

Tripathi S, Ghoshal U, Mittal B, et al (2011). Association between gastric mucosal glutathione-S-transferase activity, glutathione-S-transferase gene polymorphisms and Helicobacter pylori infection in gastric cancer. Indian $J$ Gastroenterol, 30, 257-63.

Wang Q, Chen Y, Zhang Y, et al (2014). Quantitative assessment of the influence of glutathione $\mathrm{S}$-transferase $\mathrm{T} 1 \mathrm{null}$ variant on gastric cancer risk. Tumour Biol, 35, 849-58.

Wideroff L, Vaughan TL, Farin FM, et al (2007). GST, NAT1, CYP1A1 polymorphisms and risk of esophageal and gastric adenocarcinomas. Cancer Detect Prev, 31, 233-6.

Wu MS, Chen CJ, Lin MT, et al (2002). Genetic polymorphisms of cytochrome p450 2E1, glutathione S-transferase M1 and $\mathrm{T} 1$, and susceptibility to gastric carcinoma in Taiwan. Int $J$ Colorectal Dis, 17, 338-43.

Xie SQ, Huang X, Lu YF (2008). Glutathione sulfur transferase $\mathrm{t} 1, \mathrm{~m} 1$ gene deletion and wine and tobacco habit and gastric cancer susceptibility in the Guangxi people. Clinical Focus. 19, 1393-5.

Yadav D, Chandra R, Saxena R, et al (2011). Glutathione-Stransferase $\mathrm{M} 1$ and $\mathrm{T} 1$ genes and gastric cancer: a case control study in North Indian population. Gene, 487, 166-9.

Yadav DS, Devi TR, Ihsan R, et al (2010). Polymorphisms of glutathione-S-transferase genes and the risk of aerodigestive tract cancers in the Northeast Indian population. Genet Test
Mol Biomarkers, 14, 715-23.

Ye M, Liu JY, Deng CJ (2003). Relationship between xenobioticmetabolizing enzyme gene polymorphisms and genetic susceptibility of gastric cancer. World Chin J Digestol, 9, 1314-7.

Zendehdel K, Bahmanyar S, McCarthy S, et al (2009). Genetic polymorphisms of glutathione S-transferase genes GSTP1, GSTM1, and GSTT1 and risk of esophageal and gastric cardia cancers. Cancer Causes Control, 20, 2031-8.

Zhang AP, Liu BH, Wang L, et al (2011). Glutathione S-transferase gene polymorphisms and risk of gastric cancer in a Chinese population. Asian Pac J Cancer Prev, 12, 3421-5.

Zhang W, Huang J, Peng G, et al (2013). Null genotype of glutathione S-transferase T1 contributes to increased risk of gastric cancer in Asian population. Tumour Biol, 34, 1461-6.

Zhang YC, Deng CS, Zhou Y (2003). Association of glutathione Stransferase M1 and T1 genetic polymorphisms with Helicobacter pylori infection and gastric adenocarcinoma. World Chin J Digestol, 9, 1306-9.

Zheng TR, Zheng QH, Gong FS (2002). Gene deletion polymorphisms of GSTT1 and GSTM1 and susceptibility to stomach neoplasm. Shi Yong Zhong Liu Za Zhi, 3, 155-7.

Zhou Q, Zheng ZY, Wang LD, et al (2003). Prevalence of genetic polymorphisms of GSTM1, GSTT1 and GSTP1 in subjects with gastric cardia adenocarcinoma at Linzhou, Henan. $J$ Henan Med University, 3, 327-9. 